\title{
Automated Water Irrigation System for Urban Farming
}

\author{
Hafis Murty ${ }^{1}$ and Mohd Faizal Fauzan ${ }^{1,2}{ }^{*}$ \\ ${ }^{1}$ School of Computer Science and Engineering, Taylor's University Lakeside Campus, \\ 47500 Subang Jaya, Selangor, Malaysia \\ ${ }^{2}$ Solar Energy Research Institute, Universiti Kebangsaan Malaysia, 43600 Bangi, Selangor, \\ Malaysia.
}

\begin{abstract}
The advancement in knowledge and technology has benefited various types of industries worldwide including the agricultural sector. The developments in the traditional agricultural sector has created a new type of agronomy called, urban farming. This type of farming is usually done in the city or even in housing areas and apartments. The concept of this agricultural activity is to utilise limited amounts of available space for the planting of fruits and vegetables that can grow at a quick rate. This type of farming is small-scaled and requires low initial investments. However, the issue with urban farming is that water irrigation is usually done manually using human labour and is powered by electricity which is a non-renewable energy power source. Thus, the main objective of this research paper is to produce a new and improved small-scaled automated water irrigation system for urban farming that is not only self-sustainable but also powered by renewable energy. There were three types of analysis conducted that contained the major factors affecting a water irrigation system. These analyses are renewable energy, flow and economic analysis. Besides that, main design elements were also taken into consideration such as using renewable energy as a power source (Solar, Wind or Hydro), pump and motor power, pipe size, material, layout and cost, volumetric flow rate, head loss and actual pressure present in pipes. The results of the analysis justified that hydro energy was the best renewable energy to be used as a power source. The results also showed that a $500 \mathrm{~W}$ pump and motor set was most optimum to irrigate water in the urban farm. In addition, a $0.3 \mathrm{~m}$ underground pipe layout using $3 / 4$ inch rubber pipes was proven to be the most efficient for a new and improved water irrigation system. From the economic analysis conducted, the new and improved design of automated water irrigation system for urban farming was able to save up to RM 2364.58 annually with a Return on Investment (ROI) of about 6 months while showing profit within 1 year. The analyses conducted and results obtained proved that the new and improved design of automated water irrigation system for urban farming is not only cost efficient but is also environmentally friendly.
\end{abstract}

\footnotetext{
*Corresponding author :drfaizalfauzan@gmail.com
} 


\section{Introduction}

In this modern-day and age, there are plenty of advanced gadgets, machines and appliances being used worldwide in various industries such as construction, education and transport to further simplify the processes involved, increase the efficiency of processes and lessen the burden of manual work required from humans. Technology has come a long way in helping to not only bolster the quality of products being obtained by consumers but also strengthen the economy of countries worldwide [1]. This is mainly due to the international trade of knowledge and technology between the developed countries and the developing countries. This trade benefits both parties as the developing countries can obtain more modern technology to boost their economy and the developed countries create an alliance with the countries involved while further strengthening their economy from the trade of information [1]. Of the many industrial sectors that are modernized by technology, the agricultural sector still has many potential avenues that can be explored to further enhance the end products and simplify the farming process.

Agriculture is the skill of producing crops, livestock and fertilizing soil which leads to the trading and marketing of these products to potential buyers [2]. In layman terms, the public's idea of agriculture generally involves a plot of land with vegetable and fruit plants being grown or animals such as cows and sheep being bred. In Malaysia, the agricultural sector contributes to $12 \%$ of the country's annual Gross Domestic Product (GDP) value [3]. This industry also provides jobs for $16 \%$ of the nation's population. The Ministry of Agriculture and Agro-Based Industry (MOA) provides incentives and assistance to current and new farmers who want to make a living through agriculture. This is to further promote the agricultural industry as a potential source of income for those who are considering this field of work [4]. However, not everyone wants to do agriculture as a full-time job. This is due to a few factors such as the maintenance of a large plot of land, the large investments required to yield profit and the physical exhaustion from farming. Another issue is that those who live in high raised buildings such as apartments and condominiums or those who live in highly populated areas (cities, towns) such as Kuala Lumpur find empty land hard to come by. Some people view agriculture as a past time or hobby that can be done whenever there is free time. It can also be a family activity to bond with each other. Therefore, the lack of land in certain areas and the reluctance of full-time commitment to agriculture lead to a newer user-friendly version called urban farming.

Urban farming also known as urban agriculture is an activity where plants (vegetables/ fruits) and food are produced in a city or highly populated area (towns) [5]. Examples of urban farms are as shown in Figure 1. The popularity of urban farming has been growing over the past decade not only in other countries but also in Malaysia. Many local urban farmers have been discovered and interviewed by media companies such as The Star and The Sun Newspaper [6]. The farmers have grown crops such as chili, cherry tomato and 'Pak Choy' all in the convenience of their backyard. There are many ways to carry out urban farming such as using rooftop greenhouses, vertical farms and community gardens. The concept of urban farming attracts people to do it part-time or as a hobby because:

- Small scale farming = Can be done in lawns, porches or even in apartments/ condominiums.

- $\quad$ Not time-consuming = Plants can grow by natural sunlight and rainwater. Watering only needs to be done a day if there is no rain. Fertilizers either are not required or small amounts monthly.

- $\quad$ Low cost $=$ Plants grown in urban farming are small in numbers and have low maintenance costs [6]. 


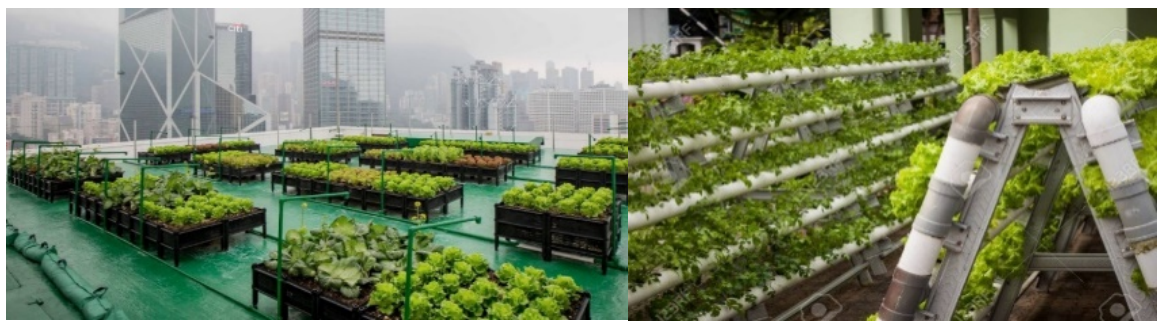

Fig 1. Urban Farming Examples.

Even with such alluring features, urban farming has challenges that need to be overcome. One major factor is dealing with the water irrigation system. Water irrigation is the distribution of water to soil at certain time intervals using a variety of systems such as pumps, sprays and tubes [7]. There are also many types of irrigation systems such as surface, drip and sprinkler irrigation. Water irrigation systems are usually handled manually (by humans) or semi-automatically whereby the water is distributed by itself with the turn of a switch and monitored by humans [7]. The issue with this is that human control is still required which means extra labour costs. This can be overcome by using an automated water irrigation system.

However, automatic water irrigation systems are costly and not commonly made for small scale farming [8]. In addition, automatic systems have limited functions and thus have research potential to be improved on. Hence, the purpose of this project is to not only research and build an improved automated water irrigation system for urban farming but also make it cost-efficient, sustainable, a variety of additional features and applicable to both small and big-scale farming. The motivation to take on this research project is the wide-ranging possibilities for improvements of automatic water irrigation systems and a family background of farming. Besides that, this project also addresses one of the 14 Grand Challenges set by the National Academy of Engineering (NAE) which is to restore and improve urban infrastructure [9].

Furthermore, this project is done in collaboration with Sekolah Menengah Kebangsaan (SMK) Bandar Sunway which is one of the first and well-known local government schools to carry out urban farming in education [10]. The school is under Sunway's Seeding Inspiration and Leadership via Knowledge (SILK) program started by Tan Sri Dr. Jeffrey Cheah in an effort to focus on the schools built by local communities. The program mainly consists of Form 2 students and is supervised by teachers and volunteers [10]. The aim of this program is to educate the younger generation on agriculture through urban farming as a potential career path via a more hands-on method. The program is also designed to promote volunteerism among Sunway's staff members. Hence, this collaboration between SMK Bandar Sunway and Taylor's School of Engineering has high hopes and expectations to design a new and improved automated water irrigation system for urban farming.

As for this research, there are three specific objectives aimed to be fulfilled. The first objective is to select the best renewable energy source that can be used to power an automated water irrigation system in Malaysia by comparing various sources of energy. The next one is to compare and select the best piping system, pump and motor for optimum water pressure in an automated water irrigation system. The final objective is to design a cost-efficient automated water irrigation system prototype that has added features such as heat, rain and light sensors along with a programmable list of plant types for small-scale urban farming. The findings from this research and experiments are expected to promote sustainability and the use of renewable energy as the main source of power for farming activities in Malaysia since renewable energy is not widely used in farming activities in this country although prior analysis and research work has been carried out. 


\section{Key Design Elements}

The main theory behind a new and improved automated water irrigation system for urban farming is to eliminate the need of human (manual) labor whilst being powered by a sustainable, reusable and renewable energy source. In this research paper, the final automated water irrigation system design will be created using the Solidworks software. The design will be simulated rather than being built due to the recent COVID-19 pandemic and lockdown restrictions (CMCO) by the Malaysian Government. However, the final design will incorporate certain key design factors that will justify the improvements required in current water irrigation systems. The main elements being studied are as follows:

- In depth analysis of 3 main renewable energy sources in Malaysia namely, solar, wind and hydro/ water energy.

- Optimum pump and motor power rating.

- $\quad$ Pipe size, material and layout.

- Volumetric flow rate, head loss and actual pressure present in respective pipe sizes.

- Cost of pipes based on size and material.

Lastly, a detailed economic analysis will be carried out on the new and improved design to compare the cost efficiency with current available designs. The potential Return on Investment (ROI) and annual savings using the new design are also calculated.

\section{Methodology}

\subsection{Comparison of renewable energy sources}

The conventional automated water irrigation system is usually powered by electricity or a rechargeable battery source. As stated in the literature review section, a lack of development in renewable energy power sources for automated water irrigation systems in urban farms provides a potential challenge to be researched and improved upon. To achieve this objective, renewable sources such as solar, wind and water are selected. This is because these energy sources are readily obtainable and applicable to the agricultural sector, making them easier to work and test with. In addition to that, Malaysia has an abundant supply of these renewable energy sources. However, it should be considered that the renewable energy sources stated are not constantly being supplied rather that these sources are intermittent. This means that the renewable energy sources to be tested are dependent on time and season.

Therefore, to determine the best renewable energy source that can be used to power the automated water irrigation system, the power output of solar, wind and water/ hydro energy in Malaysia was determined and calculated based on the intermittent work output data obtained from reliable sources such as the country's Energy Commission Department. The aim of using these data was to calculate which renewable energy source produced the highest power output based on Malaysia's various time and seasons. In addition, the efficiency of each energy source was calculated. The formulas to obtain these values are as shown [11]:

$$
\begin{gathered}
\text { For Solar Energy, Output Power }=\frac{\text { Irridiance Level } \times \text { Area }}{\text { Time }} \\
\text { For Wind Energy, Output Power }=\text { Wind Density } \times \text { Area }
\end{gathered}
$$


For Water or Hydro Energy, Output Power

$$
\begin{aligned}
& \quad=\text { Volumetric flow rate } \times \text { Density } \\
& \quad \times \text { Gravitational Acceleration } \times \text { Height } \\
& \quad \times \text { Global Efficiency Ratio } \\
& \text { Efficiency }=\frac{\text { Calculated Power }}{\text { Theoretical Power }} \times 100 \%
\end{aligned}
$$

By considering parameters such as the number of renewable energy cells to be used, type of motor to be powered and time is taken to power a motor, the power output and efficiency of each renewable energy source can be obtained with better accuracy. Furthermore, the results obtained was put in a decision matrix table along with other factors that potentially affected the selection of a renewable energy source. The top 2 sources with the highest weightage of scores was selected and combined. The idea of combining the top 2 renewable energy sources was to ensure that the automated water irrigation system had enough power to operate without the use of external non-renewable energy sources.

\subsection{Selection of piping, pump and motor system}

As stated in the scope and limitation part of this project, the types of pipes that were going to be considered for this research project are rubber and PVC pipes. This is mainly due to their low cost and common use in the agricultural sector. Although metal pipes are stronger, they are much more costly and tend to rust in the presence of water and air which are elements abundantly available in agriculture. After selecting the two most suitable material of pipe, the optimum dimensions of pipe for the final design was calculated by using formulas from fluid mechanics such as fluid pressure, pressure loss, volumetric flow rate and head loss in pipes [12].

$$
\text { Volumetric Flow Rate }=\text { Area } \times \text { Velocity of Water }
$$

$$
\begin{aligned}
& \text { Fluid Pressure }= \text { Atmospheric Pressure } \\
&+(\text { Density } \times \text { Gravitational Acceleration } \times \text { Height }) \\
& \frac{\text { Pressure Loss }}{\text { Length of Pipe }}=\text { Darcy Friction Factor } \times \frac{\text { Density }}{2} \times \frac{\text { Velocity }^{2}}{\text { Diameter of Pipe }}
\end{aligned}
$$

For pump and motor selection, the power rating tested was around $300 \mathrm{~W}$ to $500 \mathrm{~W}$. This was due to the small size of the urban farm used in this project. Three different pumps and motors was tested to determine which one was the most efficient and produced the highest power output. The test was done by comparing three different models of pumps and motors. The model and power rating of each pump was $300 \mathrm{~W}, 400 \mathrm{~W}$ and $500 \mathrm{~W}$ respectively. This was to indicate that three different levels of power namely, low, medium and high respectively were considered and tested to determine which pump and motor set was enough to power the automated water irrigation system. If a low power rating pump was found to be sufficient while taking into consideration the efficiency, then that pump will be the one selected as a low power rated pump was cheaper. Hence, cost efficient. By using equations (1) and (2), the power output and efficiency of each pump and motor set was calculated. The results were then put in a decision matrix table along with other factors that potentially affected the selection of pumps and motors.

As for pipe size, layout and material selection, there were two parts to this analysis. The first part considered the pipe size and layout. Three different pipe sizes and layouts were 
considered for this part of the analysis. The pipe sizes chosen which were, $1 / 4$ inch, $1 / 2$ inch and $3 / 4$ inch respectively, were the ones most used in the agricultural sector. The layout of the piping system was also taken into consideration as it had the potential to affect the amount of pressure loss by the system. Pressure loss occurred when there was a change in elevation of piping (Pipes are not horizontally assembled) and when fluid passed through pipe bends, valves and fittings. Therefore, these factors must be taken into consideration when designing the layout of the piping system in order to maintain optimum pressure in the pipes. The layouts tested for all three types of pipes were surface level, above ground and underground layout. The length of pipe was kept constant for more accurate results. In addition to that, the volumetric flow rate, fluid pressure and head loss in all three pipes was calculated using equations (5) to (7) for all three layout conditions. The best results of pipes based on layout was put in a decision matrix table along with other factors that potentially affected the selection of pipe size and layout.

The next part of the analysis was determining the best pipe material to be used by evaluating the cost of using each material. The two materials considered were PVC and rubber pipes. For this part of the analysis, a price comparison was conducted to compare the price of each size of pipe using both materials selected.

\subsection{Cost-efficient prototype design with added features and programmes}

Once all the other factors have been analysed and decided upon, the best optimum materials and equipment obtained using decision matrix systems from all the study conducted was incorporated together into a final design for an automated water irrigation system for urban farming. Besides that, current available designs obtained from the Literature Review section was also compared to each other in terms of costing and feasibility level.

Next, the new and improved design of automated water irrigation system for urban farming will be analysed in terms of cost of electricity consumption and labour. This is because the themes of this project are renewable energy as a replacement for electricity (nonrenewable energy) to power a pump/ motor system for water irrigation and an automated water irrigation system for urban farming as a substitute for manual labour. The cost of each item was taken and the total cost was compared to the ones of current designs. To further justify the selection of the new and improved design, a Return on Investment (ROI) analysis was conducted based on criteria stated.

The formula of ROI is as listed below [13]:

$$
\text { Return on Investment }(\mathrm{ROI})=\frac{\text { Initial Cost of New Design }}{\text { Initial Cost of Old Design }} \times 12 \text { months }
$$

In addition to that, a concept design of the new and improved automated water irrigation system for urban farming will be created using the Solidworks application.

\section{Results and Discussion}

\subsection{Renewable energy analysis}

As stated in the first part of the Research Methodology section, tests and studies were to be conducted to determine the most suitable renewable energy source that could be used to power the automated water irrigation system. The required data of renewable energy sources 
such as solar, wind and water/ hydro were obtained from official government sources such as the Energy Commission of Malaysia and reliable published journals that investigated the amount of work produced by various renewable energy sources in Malaysia [14]. The data was based on local readings since this research project is being carried out in Malaysia. The intermittent conditions for each renewable energy source were also considered. The data was then interpreted into tables and graphs.

Based on the analysis of all three renewable energies, the average monthly power output in Malaysia of each source was obtained. This is as shown below in Table 1.

Table 1. Table of calculated results of average monthly hydro energy power output based on states and Federal Territories in Malaysia.

\begin{tabular}{|c|c|}
\hline Renewable Energy Source & Average Monthly Power Output in Malaysia (kW) \\
\hline Solar & 20897.72 \\
\hline Wind & 347.55 \\
\hline Hydro/ Water & 228669.1 \\
\hline
\end{tabular}

As seen in Table 11, the highest average monthly power output in Malaysia was produced by Hydro energy. This was followed by solar and wind energy respectively.

Before comparing all three renewable energy sources using a decision matrix system, the average cost of one piece of equipment to generate power using each source was calculated. For an even result, the cost of equipment to generate $50 \mathrm{~kW}$ of power was taken into account. This is because $50 \mathrm{~kW}$ is the maximum average monthly power required to run an automated water irrigation system for urban farming based on the research conducted in the Literature Review section. The costs are shown below in Table 2.

Table 2. Table of calculated results of average monthly hydro energy power output based on states and Federal Territories in Malaysia.

\begin{tabular}{|c|c|}
\hline Renewable Energy Source & $\begin{array}{c}\text { Average Cost of One Renewable Energy } \\
\text { Converter and Power Generator (RM) }\end{array}$ \\
\hline Solar & 1500 \\
\hline Wind & 1000 \\
\hline Hydro/ Water & 2500 \\
\hline
\end{tabular}

As seen in Table 2, the highest average cost of equipment was for Hydro energy. This was followed by Solar and Wind energy, respectively. With all the data obtained, all three renewable energy sources were further compared using a decision matrix table. This is as shown below in Table 3.

Table 3. Decision matrix system for renewable energy selection.

\begin{tabular}{|c|c|c|c|c|}
\hline Criteria & Weightage & Solar Energy & Hydro Energy & Wind Energy \\
\hline Power Output & $\mathbf{5}$ & 4 & 5 & 3 \\
\hline Efficiency & $\mathbf{5}$ & 3 & 4 & 5 \\
\hline $\begin{array}{c}\text { Year-Round } \\
\text { Availability of } \\
\text { Renewable } \\
\text { Energy Source }\end{array}$ & $\mathbf{4}$ & 4 & 5 & 3 \\
\hline Cost & $\mathbf{4}$ & 4 & 3 & 5 \\
\hline Feasibility & $\mathbf{3}$ & 5 & 4 & 3 \\
\hline Aesthetics & $\mathbf{1}$ & 5 & 5 & 5 \\
\hline \multicolumn{2}{|c|}{ Sum of Scores } & 87 & 91 & 86 \\
\hline
\end{tabular}

Based on the decision matrix system in Table 3, the renewable energy source with the highest sum of scores was Hydro energy. This is followed by solar and wind energy, 
respectively. Higher scores given for each criterion indicated better power output, higher efficiency, year-round availability, lower cost, greater feasibility and decent aesthetics based on results obtained. In terms of power output, year-round availability and aesthetics, Hydro energy received that best scores possible due to a better performance level than the other two energy sources. Although Hydro energy did not have the best efficiency, cost and feasibility, this source of energy proved to be reliable and a valid option to power an automated water irrigation system for urban farming based on the results calculated. Thus, Hydro energy was chosen as the most suitable renewable energy source to power the automated water irrigation system. Further analysis and design using Hydro energy as the main power source was conducted in the economic analysis section.

\subsection{Flow rate analysis}

In this section, there were two parts in the analysis conducted. The first part of the analysis was to study and test 3 different pump and motor power ratings to determine the most suitable model to power the automated water irrigation system. The power rating of each pump to be tested were $300 \mathrm{~W}, 400 \mathrm{~W}$ and $500 \mathrm{~W}$ respectively. These 3 models were chosen because these were the most common power ratings of pumps used for small scale water irrigation systems. The next part of the analysis involved the selection of pipe material and size followed by analysing the potential pressure/ head loss experienced by 3 different pipe setups. These piping setups were based on the size of the urban farm in SMK Bandar Sunway. The results of the analysis were explained in detailed in the following sections.

Based on the results obtained and the graphs plotted for the first part of the analysis, all tested pump and motor models had a monthly power requirement of below than $50 \mathrm{~kW}$ which was the maximum average monthly power required to run an automated water irrigation system for urban farming based on the research conducted in the Literature Review section. This means that all 3 types of renewable energy sources analysed in the previous section were able to the power the automated water irrigation system as all 3 models of pump and motor require less than $50 \mathrm{~kW}$ of power monthly. However, it can be observed that the actual power output of a pump/ motor is $18 \%$ less than the power rating. The lower power output may be caused by energy that is lost in the form of heat, friction and mechanical work. Besides that, it can also be seen that the monthly power required by the pump/ motor with addition power considered increased as the actual power output of pump/ motor increased. It can also be observed that the cost of pump/ motor increased as the power rating increased. With all the data obtained, all three models of pump/ motor were further compared using a decision matrix table. This is as shown in Table 4.

Table 4. Decision matrix table for pump and motor selection.

\begin{tabular}{|c|c|c|c|c|}
\hline \multirow{2}{*}{ Criteria } & \multirow{2}{*}{ Weightage } & $\begin{array}{c}\text { Pump/ Motor } \\
\text { A }\end{array}$ & $\begin{array}{c}\text { Pump/ Motor } \\
\text { B }\end{array}$ & $\begin{array}{c}\text { Pump/ Motor } \\
\text { C }\end{array}$ \\
\hline Power Output & $\mathbf{5}$ & 3 & 4 & 5 \\
\hline Efficiency & $\mathbf{5}$ & 4 & 4 & 4 \\
\hline Cost & $\mathbf{4}$ & 5 & 4 & 3 \\
\hline Feasibility & $\mathbf{3}$ & 4 & 4 & 4 \\
\hline Aesthetics & $\mathbf{1}$ & 3 & 3 & 3 \\
\hline \multicolumn{2}{|c|}{ Sum of Scores } & 70 & 71 & 72 \\
\hline
\end{tabular}

As seen in the decision matrix in Table 4, the pump/ motor with the highest final score was Pump/ Motor C. This was followed by Pump/ Motor B and A respectively. Although Pump/ Motor $\mathrm{C}$ was the most expensive, the power output characteristics of this model outweighs the cost factor. A higher power output required more energy as compared to the 
other two pumps. However, this meant that Pump/ Motor C was more than capable of irrigating water throughout the urban farm based on the area and time specifications set. Thus, this made Pump/ Motor C the most suitable model to be used to generate water movement in an automated water irrigation system for urban farming. Nonetheless, the other two pumps were also capable to be used even with a lower power output. Further analysis and design using Pump/ Motor C as the main water movement generator was conducted in the economic analysis section.

The second part of the flow analysis was the selection of pipe size, layout structure and material. 3 different pipe sizes and layouts was considered for this part of the analysis. The pipe sizes chosen which were, $1 / 4$ inch, $1 / 2$ inch and $3 / 4$ inch respectively, are the ones most used in the agricultural sector.

The second part of this analysis combines a few factors of piping. The factors considered here were size of pipe, layout and potential head (pressure) loss in pipes. To increase the accuracy of results, certain factors were taken as constant for all sizes of pipes. The data was analysed and the results obtained were calculated as shown in the tables and graphs that follow. A drawing of all potential pipe materials, layouts and sizes was created using the Solidworks application as shown in Figures 2 and 3.

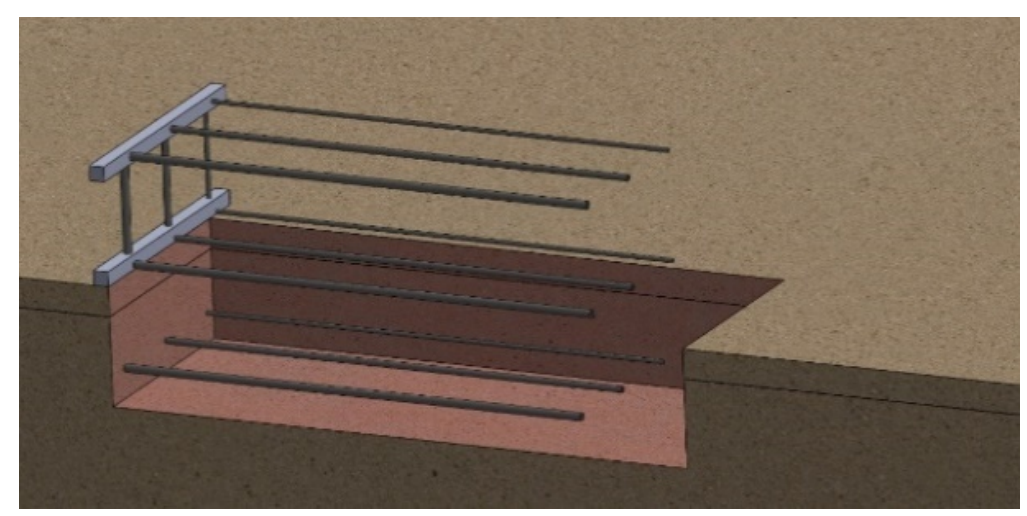

Fig 2. $0.3 \mathrm{~m}$ above ground, surface level and $0.3 \mathrm{~m}$ underground layout of $1 / 4$ inch, $1 / 2$ inch and $3 / 4$ inch (from right to left) pvc pipes.

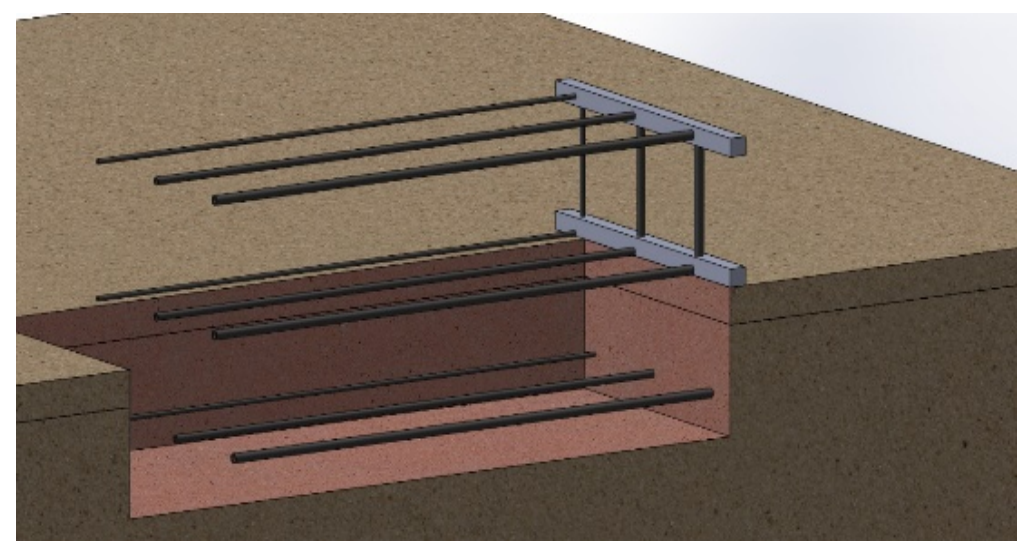

Fig 3. $0.3 \mathrm{~m}$ above ground, surface level and $0.3 \mathrm{~m}$ underground layout of $1 / 4$ inch, $1 / 2$ inch and $3 / 4$ inch (from left to right) rubber pipes. 
Based on the results, the pressure (head) loss in pipes decreased with an increase in size of the pipe itself. From this, it can be observed that the actual pressure in pipes was greater when the pipe size itself increased. This was because as the fluid pressure being supplied to all sizes of pipes remained constant, the pressure loss in each pipe decreased with an increase in size of pipe. Actual pressure in pipes was the difference between the fluid pressure and the pressure loss. Therefore, as the pressure loss decreased with an increase of size of pipe and the fluid pressure remained constant in all sizes of pipes, the actual pressure was found to be increasing with an increase of pipe size. However, it can also be said based on the results that the fluid pressure was dependent on the pipe layout. In addition to these, it can also be seen in the tables and graphs obtained that the actual pressure values of pipes in a $0.3 \mathrm{~m}$ underground layout were the highest among the other 2 layouts. This was followed by the surface level and $0.3 \mathrm{~m}$ above ground layout, respectively. The reason for the $0.3 \mathrm{~m}$ underground layout of pipes having the largest actual pressure values was since this layout provides the largest fluid pressure value, $104178 \mathrm{~Pa}$, among all three layouts. Another reason for this was that the underground layout was in line with gravity. Based on the fluid pressure formula, pressure was higher when going in the same direction as gravity rather than in the opposite direction. As pressure loss was constant in all three layouts, this justified that the actual pressure produced by the $0.3 \mathrm{~m}$ underground layout was the largest among all three layouts. Hence, this made it the best layout for supplying water to plants in the urban farm since the actual pressure was the highest for all three pipe sizes and was within the recommended value of 50 to $100 \mathrm{kPa}$ as stated in the Literature Review section. However, it should be noted that the other two layouts were also capable of supplying enough water to plants in the urban farm due to the actual pressure being within the recommended value. With all the data obtained, all three sizes of pipes based on the best layout, which is the $0.3 \mathrm{~m}$ underground level layout, were further compared using a decision matrix table. This is as shown in Table 5.

Table 5. Decision matrix for pipe selection based on best pipe layout ( $0.3 \mathrm{~m}$ underground level).

\begin{tabular}{|c|c|c|c|c|}
\hline Criteria & Weightage & $1 / 4$ inch pipe & $1 / 2$ inch pipe & $3 / 4$ inch pipe \\
\hline Fluid Pressure & $\mathbf{5}$ & 5 & 5 & 5 \\
\hline $\begin{array}{c}\text { Actual Fluid } \\
\text { Pressure }\end{array}$ & $\mathbf{5}$ & 3 & 4 & 5 \\
\hline $\begin{array}{c}\text { Pressure (Head) } \\
\text { Loss }\end{array}$ & $\mathbf{4}$ & 3 & 4 & 5 \\
\hline $\begin{array}{c}\text { Volumetric Flow } \\
\text { Rate }\end{array}$ & $\mathbf{4}$ & 5 & 5 & 5 \\
\hline Feasibility & $\mathbf{3}$ & 4 & 4 & 4 \\
\hline Aesthetics & $\mathbf{1}$ & 2 & 2 & 2 \\
\hline \multicolumn{2}{|c|}{ Sum of Scores } & 86 & 95 & 104 \\
\hline
\end{tabular}

As seen in the decision matrix in Table 5 , the $3 / 4$ inch pipe size had the highest score among all three pipe sizes. This was followed by the $1 / 2$ inch and $1 / 4$ inch pipes respectively. From the criteria stated, it can be clearly seen that the $3 / 4$ inch pipe excelled in the Actual Fluid Pressure and Pressure Loss section. Although the other criteria had the same scores as the other pipe sizes, these criteria were not as significant as the previous two stated. Hence, the Decision Matrix not only justified the $0.3 \mathrm{~m}$ underground layout selection but also proved that the $3 / 4$ inch pipe was the optimum pipe size to be used in an automated water irrigation system for urban farming. This was because as the pipe size increased, the pressure loss decreased and thus, increased actual overall pressure in pipe. However, it should be noted that the other two layouts were also capable of supplying enough water to plants in the urban farm due to the actual pressure being within the recommended value. 
With the best layout and pipe size obtained, the last part of this analysis was to conduct a price comparison between the two chosen materials, PVC and Rubber, to determine which material was the most cost efficient. These 2 materials were chosen mainly due to their low cost among other piping materials and common use in the agricultural sector. Although metal pipes were stronger, they were much more costly and tend to rust in the presence of water and air which are elements abundantly available in agriculture. The price comparison table is as shown in Table 6 below.

Table 6. Price comparison of pvc and rubber pipes.

\begin{tabular}{|c|c|c|c|c|}
\hline \multirow{2}{*}{ Size of Pipe } & $\begin{array}{c}\text { Type of Pipe Material \& Cost (RM) } \\
\text { of Pipe Length per Metre }\end{array}$ & $\begin{array}{c}\text { Total Cost of Pipes for 1 Row Length } \\
\text { of Urban Farm,31.81 m (RM) }\end{array}$ \\
\cline { 2 - 5 } & PVC & Rubber & PVC & Rubber \\
\hline 1/4 inch pipe & 1.50 & 1.20 & 47.72 & 38.17 \\
\hline 1/2 inch pipe & 3.00 & 2.40 & 95.43 & 76.34 \\
\hline 3/4 inch pipe & 4.50 & 3.60 & 143.15 & 114.51 \\
\hline
\end{tabular}

Based on the price comparison conducted in Table 6, it can be seen that all sizes of pipes made from Rubber were cheaper as compared to PVC. The total cost of the selected $3 / 4$ inch pipes based on the length of the urban farm are RM 114.51 for rubber pipes and RM 143.15 for PVC pipes. It can be observed that the total price of Rubber pipe was much lower than PVC pipe. Therefore, Rubber was chosen as the pipe material to be used for further analysis in the section that follows.

\subsection{Economic analysis}

The last analysis to be conducted was the economic analysis. This section mainly focused on the comparison of costs between current designs of water irrigation systems for urban farming and a new and improved proposed design. The outcome of this analysis proved which design and concept of water irrigation system for urban farming, current or new and improved, was more cost efficient, had more added features, convenient and overall, more feasible to be used in small scaled urban farming.

The first part of this analysis examined the costing and feasibility of current water irrigation system designs (Automated \& Manual) used in farming. The designs chosen were as stated in the Literature Review section of this Thesis. For costing calculations, the area of the urban farm which is $1011.71 \mathrm{~m}^{2}$, was taken. The length and width of the farm were taken as $31.81 \mathrm{~m}$ each, respectively. Besides that, it was suggested that 20 rows of plants were to be made which meant that the irrigation system had to supply water to all these rows. The results obtained are compiled in Table 7.

From Table 7, all designs had either a high cost and low feasibility or low cost and high feasibility. There was no current design that brought a balance of cost and feasibility into the concept. Therefore, the last part of this analysis was to design and study a new and improved cost-efficient automated water irrigation system that had added features such as heat, rain and light sensors along with a programmable list of plant types for small-scale urban farming. Based on the analysis conducted in previous sections, the best optimum materials and equipment obtained using decision matrix systems were combined in this section as a basis for a new and improved design. The full costing of this proposed design is as shown in Table 8. 
Table 7. Costing and feasibility table of comparison for current designs of water irrigation system used in farming.

\begin{tabular}{|c|c|c|c|}
\hline $\begin{array}{c}\text { Design of Water Irrigation } \\
\text { System }\end{array}$ & $\begin{array}{c}\text { Country of } \\
\text { Origin }\end{array}$ & $\begin{array}{c}\text { Cost for 20 Rows of } \\
\text { Water Irrigation (RM) }\end{array}$ & Feasibility Level \\
\hline $\begin{array}{c}\text { Smart Aquaponics Automated } \\
\text { Water Irrigation System }\end{array}$ & Singapore & RM 2740.20 & Low \\
\hline Manual Water Irrigation System & Various & RM 2440.20 & High \\
\hline $\begin{array}{c}\text { Solar Energy Powered Automated } \\
\text { Water Irrigation System }\end{array}$ & India & RM 17740.20 & Low \\
\hline $\begin{array}{c}\text { Centralized Automated Water } \\
\text { Irrigation Control System for } \\
\text { Canals }\end{array}$ & USA & RM 3740.20 & Medium \\
\hline $\begin{array}{c}\text { Sprinkler based Automated Water } \\
\text { Irrigation System }\end{array}$ & Brazil & RM 4240.20 & Medium \\
\hline
\end{tabular}

Table 8. Costing and feasibility table for new and improved automated water irrigation design.

\begin{tabular}{|c|c|c|}
\hline Components Required & Quantity & Cost (RM) \\
\hline 3/4 inch rubber pipe & For 20 rows of length 31.81 m each & 2290.20 \\
\hline Arduino Board & 1 & 39.00 \\
\hline Motor Shield & 1 & 15.00 \\
\hline Heat Sensor & 1 & 86.50 \\
\hline Light Sensor & 1 & 20.00 \\
\hline PH Value Sensor & 1 & 24.70 \\
\hline Rain Sensor & For all 20 rows of water irrigation \\
(About 32 m) & 6.05 \\
\hline Wires & 1 & 25.00 \\
\hline $\begin{array}{c}\text { Software Application for } \\
\text { Plant Type Programming }\end{array}$ & 1 & 1000.00 \\
\hline $\begin{array}{c}\text { Hydro/ Water Generator } \\
\text { and Energy Converter }\end{array}$ & 1 & 2500.00 \\
\hline Pump and Motor Set C & & 261.70 \\
\hline \multicolumn{2}{|c|}{} & \\
\hline
\end{tabular}

Based on Table 8, the new and improved design of automated water irrigation system for urban farming was more costly than some of the current designs as stated in Table 7. The costing obtained made this new design look like an unviable option. However, the total cost of this new design can be justified using a Return on Investment (ROI) analysis. This was because the main focuses of this project are renewable energy as a replacement for electricity (non-renewable energy) to power a pump/ motor system for water irrigation and an automated water irrigation system for urban farming as a substitute for manual labour. Thus, the key points analysed based on this statement was the cost of electricity power consumption and the cost of hiring workers. The ROI, savings and any other related costs were calculated as shown in Table 9 to further justify this new and improved design. A factor that was also taken into consideration for the ROI calculations to be more accurate is that there is a total of 20 rows of plants. On average, plants needed to be about $1.6 \mathrm{~m}$ apart from each other in a row. Each row was $31.81 \mathrm{~m}$ long. Thus, 1 row contained about 20 plants.

As seen in Table 9, the new and improved design was undoubtedly more cost efficient than current designs. This was because the latest design eliminated electricity and labour costs. This in turn decreased the total initial cost of the new design and made it much cheaper than current designs. The ROI calculated showed that by using the new and improved design, the investments made can be obtained back in about 6 months which was a relatively short amount of time. This meant that profits can be made by using the new design within one year. Besides that, the cost savings calculated also indicate that the new design was able to save 
up to RM 2363.58 annually. Thus, the analysis conducted proved that the new and improved design was not only cost efficient, but also environmentally friendly as it eliminated the need of electricity (Non-renewable energy) as a main source of power.

Table 9. Initial cost and ROI.

\begin{tabular}{|c|c|c|}
\hline Type of Design & $\begin{array}{c}\text { Current Designs of } \\
\text { Water Irrigation } \\
\text { Systems (Old) }\end{array}$ & $\begin{array}{c}\text { Automated Water Irrigation } \\
\text { System for Urban Farming (New } \\
\text { and Improved Design) }\end{array}$ \\
\hline Source of Energy & Electricity & $\begin{array}{c}\text { Hydro/ Water (Natural and } \\
\text { Reusable) }\end{array}$ \\
\hline $\begin{array}{c}\text { Cost to Power Pump and } \\
\text { Motor Set per Month (RM) }\end{array}$ & 5.38 & - \\
\hline $\begin{array}{c}\text { Cost to Power Pump and } \\
\text { Motor Set per Year (RM) }\end{array}$ & 64.58 & - \\
\hline Type of Labour & $\begin{array}{c}\text { Manual (2 Workers for } \\
\text { Whole Urban Farm) }\end{array}$ & $\begin{array}{c}\text { Automated (No Workers } \\
\text { Required) }\end{array}$ \\
\hline Monthly Cost of Labour (RM) & 200.00 & - \\
\hline Yearly Cost of Labour (RM) & 4800.00 & - \\
\hline $\begin{array}{c}\text { Total Initial Cost of Design per } \\
\text { Year (RM) }\end{array}$ & 4864.58 & \begin{tabular}{c} 
Generator and Energy Converter) \\
\hline $\begin{array}{c}\text { Return on Investment (ROI) } \\
\text { when Compared to Current } \\
\text { Designs, (Months) }\end{array}$
\end{tabular} \\
\hline Yearly Cost Savings (RM) & - & 6.17 \\
\hline
\end{tabular}

\section{Conclusion}

In summary, this conference paper focused on key factors that affected the efficiency of an automated water irrigation system for urban farming and the respective economic study, to come up with an optimum design that not only eliminated the use of electricity (Nonrenewable energy source) and human (Manual) labour, but as also cost efficient and environmentally friendly by using renewable energy as a power source. The factors considered for this study were common renewable energy sources in Malaysia (Solar, Wind, Hydro), pump and motor power, pipe size, material and layout, volumetric flow rate, head loss, actual pressure present can cost of pipes. A final design was created using the Solidworks software rather than building a prototype. This was done so that costs and materials were not wasted if any changes and modifications were required. Besides that, any changes and modifications required were much easier to be done on a visual design rather than a physical one.

The economic analysis conducted was to determine whether the new and improved design was more cost efficient than current designs. The results of this analysis showed that the new and improved design of automated water irrigation system for urban farming was able to save up to RM 2364.58 annually when compared to current designs. The Return on Investment (ROI) of the new design was calculated to be about 6 months which was a relatively short period of time to get returns on the initial costs spent. The ROI also showed that profits can be obtained within the span of a year.

Overall, the study and analysis conducted in this paper were to act as a guide for future references of designs of automated water irrigation systems for urban farming. The factors considered in this paper were limited. Hence, if a new and improved design of automated water irrigation system for urban farming was to be created, more factors will need to be considered so that an optimum and accurate final design can be completed. It is recommended 
that additional pipe fittings are to be considered in the future as it may influence head loss, actual pressure and the volumetric flow rate of the water irrigation system.

\section{References}

1. T. Virasa, J. Tang, J. High. Technol. Manag. Res. 9, 195 (1998).

2. "Definition of Agriculture", Merriam-webster.com, 2020. [Online]. Available: https://www.merriam-webster.com/dictionary/agriculture.

3. "Malaysia Agriculture, Information About Agriculture in Malaysia", Nationsencyclopedia.com, 2020. [Online]. Available: https://www.nationsencyclopedia.com/economies/Asia-and-the-Pacific/MalaysiaAgriculture.html.

4. "Portal Rasmi Kementerian Pertanian \& Industri Makanan Malaysia - MOA", Moa.gov.my, 2020. [Online]. Available: https://www.moa.gov.my/.

5. "What is Urban Farming? Greensgrow", Greensgrow, 2020. [Online]. Available: https://www.greensgrow.org/urban-farm/what-is-urban-farming/. [

6. S. Chandran, "Malaysian urban farmer grows vegetables in back lane of his house in Puchong", The Star Online, 2020. [Online]. Available: https://www.thestar.com.my/lifestyle/living/2020/03/06/malaysian-urban-farmergrows-vegetables-in-back-lane-of-his-house-in-puchong.

7. "Types of Agricultural Water Use | Other Uses of Water | Healthy Water | CDC", Cdc.gov, 2020. [Online]. Available: https://www.cdc.gov/healthywater/other/agricultural/types.html.

8. "Automatic Irrigation | SSWM - Find tools for sustainable sanitation and water management!", Sswm.info, 2020. [Online]. Available: https://sswm.info/sswmuniversity-course/module-4-sustainable-water-supply/further-resources-wateruse/automatic-irrigation.

9. "Grand Challenges - 14 Grand Challenges for Engineering", Engineeringchallenges.org, $2020 . \quad$ [Online]. Available: http://www.engineeringchallenges.org/challenges.aspx.

10. "From Farm to Table - Sunway Stories", Sunway Stories, 2020. [Online]. Available: https://www.sunway.com.my/stories/from-farm-to-table/.

11. Highsmith, P., Physics, Energy, And Our World. (Philadelphia: Saunders, 1975).

12. B. Munson, T. Okiishi and W. Huebsch, Fluid Mechanics, 7th Edition SI Version, (New York: Wiley, 2013).

13. P. Kotler and G. Armstrong, Principles of Marketing, (Glob al Edition, Chicago, 2011).

14. M, Vaka, R. Walvekar, A. Rasheed, M. Khalid, J. Clean. Prod. 273, 122834 (2020). 